\title{
Corporeidade e Intersubjectividade em Husserl Algumas achegas para a compreensão do tema*
}

\author{
Maria José Cantista
}

\section{1. - Introdução}

No estado actual das investigações fenomenológicas e dos estudos efectuados sobre a noção de corporeidade e de intersubjectividade em Husserl, devemos salientar, antes de tudo, a publicação de um conjunto de textos, agrupados de forma organizada por I. Kern, e que foram editados em 1973, na edição alemã da Husserliana, nos volumes XIII-XV, com o titulo Zur Phänomenologie der Intersubjektivität. Com efeito, este conjunto de textos que abarca um longo período da fenomenologia transcendental, entre 1905-1935, obedecia a uma intenção inicial, por parte do Pai da Fenomenologia, e que continuou durante e após as Meditações cartesianas'.

Segundo I. Kern, a génese do tema da intersubjectividade em Husserl obedece a uma trilogia cronológica. Ele faz um traçado histórico da evolução da problemática da intersubjectividade, nos diversos escritos de Husserl, desde 1900-1901, até $1935^{2}$. A recente tradução parcial desta obra póstuma para francês por N. Depraz, com o título Sur l'intersubjectivité, oferece novas sugestões interpretativas, quer na introdução, quer-no-posfácio, quer no-critério-de organização-dos textos apresentados. Mais do que cronológico, o agrupamento é temático. As três figuras principais da intersubjectividade aqui destacadas prendem-se com as três formas nucleares da redução e, consequentemente, com uma diferenciação interpretativa no que à corporeidade concerne.

O fio condutor filosófico da edição proposta liga intrinsecamente a intersubjectividade e a metodologia redutiva, destacando cinco temas vectores no equacionamento da questão da intersubjectividade: primordialidade, analogização, redução intersubjectiva, antropologia, individuação.

- O presente estudo é a versão portuguesa, com algumas modificações, do artigo por nós apresentado, com o título Phenomenology: corporeity and intersubjectivity in Husserl; The most significant influences of Husserl na Encyclopedia of Learning, Phenomenology World Wide in Analecta Husserliana, Kluwer Academic Publishers, vol. 80, Verão de 2002, 743 pp. Assim se entende o carácter descritivo e preferentemente cronológico desta exposição.

1 Esta intenção é relatada por I. Kern, com o testemunho de um tex to "pages de Seefeld" de 1905. Cf. J.-L. Petit, Solipsisme et intersubjectivité. Quinze leçons sur Husserl et Wittgenstein. Paris, Cerf, 1996, p. 18.

2 I. Kern, in Encyclopedia of Phenomenology, Vol. 18, «Intersubjectivity». Dordrecht, Kluwer Academic Publishers, 1997, pp. 355-358. 
Com efeito, podemos hoje constatar a precocidade da temática da intersubjectividade na obra de Husserl. Ela foi objecto de reflexão e de reformulação constantes, ao longo de toda a sua obra e em íntima conexão com o tema da corporeidade.

Esta constatação vem contrariar a opinião comummente aceite de que, por um lado, Husserl se interessou tardiamente pela temática da intersubjectividade e, por outro lado, de que não deu grande importância ao tema da corporeidade, ao menos na primeira fase da sua obra.

$\mathrm{Na}$ verdade, a publicação desta obra póstuma e a bibliografia mais recente poderão trazer uma nova luz sobre a Fenomenologia da Intersubjectividade, exposta e desenvolvida de maneira clara por Husserl nas Meditações cartesianas (1931). Estas Meditaçôes tinham sido objecto de uma primeira elaboração nas célebres Conferências de Paris e, em seguida, nas de Estraburgo. É o próprio Husserl quem declara o teor do seu projecto: "Sobre a redução intersubjectiva, unicamente as indicações verbais superficiais, mais sistematicamente detalhadas em Estrasburgo"”.

Para além disso, Zur Phänomenologie der Intersubjektivität poderá igualmente colocar em evidência uma anterioridade desta mesma problemática em textos que antecedem a propriamente denominada fenomenologia da intersubjectividade. A publicação deste imenso corpus a que está directamente associada a questão da corporeidade, obriga a reavaliar as tradicionais interpretações sobre a compreensão husserliana do tema que nos ocupa. Tais perspectivas tinham obstinadamente afirmado uma aporia abissal entre o solipsismo transcendental do ego e a experiência do outro. A obra póstuma, de carácter complexo, denota, antes de tudo, o grande esforço efectuado por Husserl, não só sobre o problema da intersubjectividade, mas também sobre a necessidade de uma particular atenção à questão do Leib/Körper, do corpo vivente/corpo-coisa. Toda esta terminologia husserliana - Leib-Leiblich - Leiblichkeit/Körper-Körperlichkeit - vem de certa forma confirmar a génese das motivações principais da fenomenologia merleaupontiana e seu desenvolvimento posterior. "Veremos aqui desenvolvidas muitas das coisas que foram repensadas de maneira própria por Merleau-Ponty - até mesmo nos exemplos escolhidos -, que conduzem, pela análise, a paralelismos impressionantes. Merleau-Ponty era, neste aspecto, bem mais husserliano do que parecia"4.

Esta mesma ideia é afirmada por J.-L. Petit que defende a necessidade de uma cuidadosa interpretação da fenomenologia husserliana, tendo como ponto de partida a consciência intersubjectiva nas suas diversas esferas ${ }^{5}$. O maior argumento para demonstrar, através de uma hermenêutica transcendental, a importância da intersubjectividade no âmbito da filosofia transcendental husserliana, é a de nos interrogarmos sobre a questão de saber como a temática da intersubjectividade se integra no método transcendental. A segunda questão que podemos formular diz respeito à concepção do cogito husserliano, uma vez que o ego transcendental puro, parece, à primeira vista, fincar-se num solipsismo transcendental absoluto. Ora,

3 E. Husserl, Cartesianische mediationen. Einleitung. Husserliana I. The Hague, Martinus Nijhof, 1963, p. xxiv.

4 N. Depraz, Prefácio in Autour des Méditations Cartésiennes (1929-1932). Tradução francesa de Husserliana, Vol. XV, "Phänomenologie der Intersubjektivität". Grenoble, Jérôme Millon, 1998 , p. 7.

5 J.- L. Petit, Solipsisme et intersubjectivité. Quinze leçons sur Husserl et Wittgenstein. Paris, 1996, p. 21. 
é precisamente isto que vem corroborar toda uma leitura clássica da fenomenologia husserliana, ao rebater a ideia de uma constituição puramente egológica do mundo, uma constituição radicada no polo subjectivo da consciência intencional. Sendo assim, o problema da intersubjectividade deverá ser desenvolvido de forma a que possa responder a uma questão essencial: de que maneira, na fenomenologia husserliana, e dentro dos limites impostos por uma ortodoxia conceptual requerida pelo próprio Husserl, se poderão traçar as linhas genéticas essenciais do problema da intersubjectividade e da corporeidade?

Contra uma posição 'excessivamente idealista' da fenomenologia husserliana, insurge-se, por exemplo, N. Depraz na sua obra Transcendance et Incarnation-Le statut de l'intersubjectivité comme alterité à soi chez Husserl -, nomeadamente no que respeita à relação da intersubjectividade e da corporeidade. A Autora pretende fundamentar uma tese que consiste na tentativa de resolução da aporia entre o ponto de partida egológico transcendental e a experiência do 'outro'. Para isso, importa abandonar a si mesma a crítica da aporia e explicitar o enraizamento genético da experiência do outro como alteridade para si no seu sentido, simultaneamente incarnado e reflexivo. Sendo assim, a percepção do outro e a da alteridade dependem essencialmente da capacidade de abordar esse outro com o máximo de abertura, isto é, no intento de uma aproximação do outro enquanto tal. No entanto, N. Depraz adverte de imediato que a procura desta alteridade não se fará a partir de fora, mas 'dentro', sem que este 'dentro' seja em nada redutível a uma interioridade, a uma pura reflexão subjectiva, nem sequer a uma imanência da consciência fechada sobre si mesma"6.

$\mathrm{O}$ método fenomenológico utilizado nesta nova abordagem do pensamento husserliano pretende praticar uma espécie de regressão que conduza a uma fenomenalização da alteridade em si, no âmago da própria imanentização. Tal método diferencia a via cartesiana da redução, e a via psicológica. A cada uma destas vias correspondem formas diferentes da experiência transcendental do outro.

Tendo como base, por um lado, a pluralidade de posições relativas à fenomenologia husserliana e por outro, a contínua descoberta do corpus husserliano, o objecto deste nosso estudo, é, portanto, o de apresentar, a partir do sistema transcendental de Husserl, a evolução do conceito de corporeidade e de intersubjectividade, expondo, para isso, os diversos conceitos inerentes à filosofia transcendental husserliana. Vamos tentar igualmente apresentar uma certa evolução da intersubjectividade, para em seguida alcançarmos de forma gradativa a concepção de corporeidade e de corpo vivente, como expressão última de uma fenomenologia transcendental incarnada.

\section{II - Logische Untersuchungen 1900-1901}

É nas Investigações lógicas (Logische Untersuchungen Erster Band: Prolegomena zur reinen Logik (1900-1901)), que poderemos constatar uma primeira enunciação do problema da intersubjectividade. Segundo I. Kern, Husserl "já aflora

6 N. Depraz, Transcendance et incarnation. Le statut de l'intersubjectivité comme altérité à soi chez Husserl. Paris, Vrin, 1995, p. 23.

7 I. Kern, Einleitung des Herausgebers, in Zur Phänomenologie der Intersubjektivität. Erster Teil, pp. XII-XXIII. 
a temática intersubjectiva na primeira Logische Untersuchung (1901), através do aspecto da função comunicativa da expressão linguística"? .

Neste texto, Husserl fala da intersubjectividade como estando directamente ligada à expressão comunicativa. Embora Husserl não empregue o termo 'intersubjectividade', poderemos encontrar uma outra denominação semântica que conduza também à mesma ideia. $\mathrm{O}$ problema da intersubjectividade é toda aquela dimensão do discurso que diz respeito a uma comunicação entre dois interlocutores.

Segundo Husserl, nos fenómenos de comunicação expressiva, deverá existir um sentido correlativo entre aquele que fala e aquele que escuta. A conexão entre o locutor que se quer fazer exprimir e o auditor que quer compreender a intenção daquele que fala, só é possível, se existir uma correlação. "O complexo fónico articulado (e isto vale também para o caractere realmente escrito, etc.) só se torna palavra falada, discurso comunicativo em geral, quando aquele que fala o produz, somente com a intenção de se exprimir sobre qualquer coisa. Por outras palavras, quando aquele que fala, lhe confere, em certos actos fisicos, um sentido que ele quer comunicar àquele que o escuta. Ora esta comunicação torna-se possível, porque o auditor compreende então a intenção daquele que fala"». $\mathrm{O}$ discurso comunicativo só se efectua, quando no discurso enunciativo se estabelece uma relação entre fenómenos físicos e vivências psíquicas. Falar e escutar implica uma relação entre a manifestação (Kundgabe) dos fenómenos psíquicos no acto de falar e os actos de apreensão (Kundnahme) por aquele que escuta. "Falar e escutar, a manifestação (Kundgabe) das vivências psíquicas no acto de falar, e a apreensão (Kundnahme) destas, no acto de escutar, são correlativas"'. Do mesmo modo, encontramos o desenvolvimento desta distinção nas Meditações cartesianas, onde Husserl distingue os fenómenos de presentação (Gegenwärtigung) ou presença originária, à qual corresponde a 'percepção', e os fenómenos da apreensão indirecta, ou apresentação (Vergegenwärtigung). Na verdade, esta distinção é fundamental visto especificar o modo de percepção originária que caracteriza o ego transcendental e o modo de apercepção do outro, isto é, o modo de apreensão indirecta do outro, característico da alteridade ${ }^{10}$. A justificação desta distinção fenomenológica leva Husserl a concluir sobre a necessidade intrínseca de reajustar a noção de intencionalidade: "Se o que é próprio do outro me fosse acessível de um modo directo, o outro seria apenas um momento daquilo que me é próprio e portanto eu e ele seríamos o mesmo" "I. Esta perspectiva é já pré-anunciada nas Logische Untersuchung visto que, apesar de Husserl afirmar a necessidade de uma correlação entre as vivências dos actos psíquicos e os actos de apreensão, não existe, contudo, uma perfeita identidade entre eles. "A compreensão recíproca exige precisamente uma certa correlação destes actos psíquicos, que se desenvolvem de ambos os lados, na manifestação e na apreensão, mas não exige de maneira alguma a sua completa identidade"12. Como se pode verificar, Husserl mantém aqui uma clara distinção e uma não-identificação, no processo de expressão comunicativa, entre os fenómenos internos e a percepção externa desses fenómenos. Porém, para que

8 E. Husserl, Recherches Logiques, tome II-Recherches pour la phénoménologie et la théorie de la connaissance. Traduit de l'allemand par H. Elie, L. Kelkel et R. Schérer. Doravante nós utilizaremos L.U. II, § 7, pp. 23-24.

9 Ibidem.

10 Esta distinção é também evidente nas Ideen II $\S 45$.

11 Méditations cartésiennes, § 50.

12 Recherches logiques, II, §7, p. 42. 
haja comunicação, é necessária uma certa correlação (Korrelation) e uma permuta espiritual para que se estabeleça uma relação entre duas pessoas no discurso. "A única coisa que torna possível a troca espiritual (geistiger Verkeher) e faz do discurso um discurso que estabelece uma ligação entre duas pessoas, reside nesta correlação mediatizada pelo aspecto físicơ do discurso"'13 .

Esta fenomenologia da expressão intersubjectiva coloca em evidência uma relação entre o eu e o tu, entre o Kundgabe e o Kundnahme, necessária a toda a função comunicativa da expressão linguística. Esta troca espiritual, da qual fala Husserl a propósito de um discurso comunicativo, só é possível através de uma série de vivências psíquicas e físicas que se pertencem mutuamente. Para Husserl, trata-se de compreender agora a natureza desta manifestação, para que se possa perceber que tipo de relação se estabelece entre aquele que fala e aquele que escuta. "A compreensão da manifestação não é um saber conceptual acerca desta última, um juízo do género da enunciação; pelo contrário, ela consiste simplesmente naquilo que o auditor apreende intuitivamente daquele que fala como uma pessoa que exprime isto ou aquilo, ou ainda simplesmente e como nós podemos dizer, que ele o percebe como pessoa. (...). A linguagem corrente confere-nos uma percepção das vivências psíquicas dos outros enquanto pessoas, nós 'vemos' a sua cólera, a sua dor etc."14. A relação que se estabelece neste acto comunicativo é entre aquele que fala e que transmite vivências exprimidas, isto é, vivências psíquicas enquanto 'doadoras de sentido', e aquele que apreende através de uma simples percepção da manifestação. Apesar da compreensão da manifestação estabelecer uma relação recíproca, esta não poderá ser, no entanto, uma relação de identidade. Desta forma, Husserl estabelece uma diferença essencial entre os actos intencionais daquele que fala e a percepção externa das vivências afectivas exprimidas. Esta diferença consiste então numa relação assimétrica entre os actos vividos e os actos percepcionados.

Num outro texto, designado por páginas de Seefeld, um manuscrito de trabalho destinado à publicação e da mesma época das Logische Untersuchungen, só agora conhecido, sendo publicado por I. Kern e integrado na Husserliana XIII, Husserl declarava já, a propósito da intersubjectividade: "Eu faço também uma experiência em relação ao outro. (...) Eu vejo o outro, mas os seus fenómenos não me são dados. Evidentemente, se eles me fossem dados, seriam meus e não seus, porque um fenómeno só pode pertencer ao contexto único eu (...). À aparência que eu tenho do meu corpo, isto é, ao lugar presente do meu corpo, eu não posso aceder ao mesmo tempo que a um outro ponto de vista. Mas a um 'outro' que precisamente agora e num outro lugar pode ter a mesma aparência"15.

\section{III - Aus der Vorlesungen Grundproblem der Phänomenologie 1910}

Die Idee der Phänomenologie. Funf Vorlesungen é um texto que consiste numa série de lições apresentadas em 1907 em Gottingen. Este texto apresenta uma leitura fundamental para uma teoria da redução fenomenológica que será depois estabelecida finalmente nas Ideen. Os problemas da intersubjectividade e da corporeidade poderão aqui ser perspectivados sob o ângulo das duas noções

is Citado por J.-L. Petit, Solipsisme et intersubjectivité. Quinze leçons sur Husserl et Wittgenstein, p. 18 . 
fundamentais de imanência e de transcendência. É a partir destes dois conceitos que poderemos perspectivar melhor a experiência do outro.

Segundo I. Kern, o manuscrito das lições de 1910, Aus der Vorlesungen Grundprobleme der Phänomenologie era conservado conjuntamente com Funf Vorlesungen de 1907, onde Husserl aborda a redução fenomenológica enquanto redução universal intersubjectiva, a redução fenomenológica e a teoria transcendental da Einfuhlung ${ }^{16}$.

Por esta altura, Husserl debatia-se já com a concepção de Einfühlung, e da experiência do outro, de Theodor Lipps. Na verdade, Husserl apresenta uma concepção diferente da concepção de intersubjectividade proposta por Lipps, e que poderá ser balizada em três pontos essenciais. Husserl descreve desde 1905 uma primeira concepção de Einfühlung como pertencendo a uma esfera estesiológica (ästhesiologische Schicht) isto é, a uma esfera de sensações que ele próprio nomeia como Leibkörperlichkeit. Um segundo aspecto, diz respeito à ideia de Lipps quanto à Einfühlung como projecção imediata e fusional nas vivências do outro. Husserl não a entende desta maneira, visto que a Einfühlung, em seu entender, é uma experiência mediata. Por tal motivo, o Autor fala de Kompräsentation ou mesmo de Appräsentation ou ainda de co-percepção, Mitwahrnemung. Encontramos, finalmente, uma concepção positiva da Einfühlung, como sendo uma experiência analógica, que é elaborada em contraposição à de Lipps. Esta experiência analógica do outro consiste em compreender e interpretar o fenómeno da exterioridade do corpo do outro, graças a uma complexificação da experiência interna.

Com efeito, Husserl procura desde 1909 uma concepção de Einfühlung, enquanto apercepção mediata e que vem precisamente corroborar a concepção lipsiana. Encontramo-la num texto da Husserliana XIII onde ele afirma:

"[...] Apercepção significa aqui a consciência objecto trancendente e eu só posso constituir a transcendência sob a forma a consciência que 'intenciona' e exige, segundo modos motivados, um preenchimento [...]. Como deverá uma apercepção ser estruturada, uma vez que é obrigada a realizar-se segundo a analogia da apreensão da carne pelo sujeito desta earne originária [?] E é preciso mostrar (em oposição à doutrina dos instintos) que a apercepção da carne estrangeira não o pode ser de forma principial, contrariamente à apercepção da minha carne (que pode e deve sê-lo), uma apercepção imediata, original, e portanto, que na comparação das duas apercepções, uma diferença de originariedade deve subsistir"17.

$\mathrm{O}$ outro tem uma esfera que lhe é própria e que constitui a sua própria carnalidade. Entre a minha carnalidade e a carnalidade do outro, é necessário um espaço de mediação, dado que a corporeidade originária diz respeito a cada um.

A importância que reveste a descrição do eu, enquanto posição mediana, Mittelpunkt e a relação que este eu indivual e singular estabelece com os outros "eus", reveste-se da maior importância. Para cada eu, os outros não são Mittelpunkt mas Umgebungspunkt, isto é, pontos de vizinhança. Cada eu é um ponto zero sistema de coơrdenadas. O corpo é um coisa por entre muitas coisas, e mantém uma relação com o eu enquanto experiência particular dentro do género de vivências percepcionadas pelo eu.

16 I. Kern, Einleitung des Herausgebers, in Zur Phänomenologia der Intersubjektivität, Husserliana XIII, p. XXIV. Traduction française par J. Englisch. Problèmes fondamentaux de la phénoménologie. Paris, PUF, 1990.

17 Zur Phänomenologie der Intersubjektivität. Husserliana XIII, n. ${ }^{\circ} 2,24$. Cf. N. Depraz, op. cit., p. 146. 
No apêndice XXIX ao §39, destas Vorlesungen, e que data de 1912, Husserl debruça-se sobre a 'corporeidade enquanto mediação dos espíritos'. Através do fio condutor da argumentação, Husserl conclui que a corporeidade mediatiza. Ele parte a questão extremada de reductio ad absurdum: como seria possível uma realidade espiritual, isto é, o sujeito-Eu sem corpo? Os corpos são por natureza qualquer coisa e são lugar de sensações e de movimento. Sendo assim, toda a experiência do eu é que sensaciona, que tem sentimento e vontade; mas se não tivesse corpo físico, não teria então um corpo que pudesse ser visto e que pudesse ser dado como objecto coisal. O corpo possui uma determinação física que permite identificá-lo como qualquer coisa lá. Da mesma maneira, ele deve ser tocado. Husserl acaba por concluir que existe uma identidade entre as séries de aparições do corpo enquanto coisa física, e as qualidades correspondentes ao espírito, como coincidentes. Por outras palavras, existe uma certa cognoscibilidade desta compreensão mútua entre aparição e espírito, como idênticos entre si. Reside nesta mesma identidade uma certa compreensão intersubjectiva. "Ora se a mesma coisa (dasselbe Ding) que a que está aí, o meu corpo enquanto coisa física, deve poder ser tocada pelo outro, então, esta identidade significa que as minhas séries de aparição e as correspondentes ao espírito, constituem, em si, a mesma coisa (dasselbe); e a identidade exige a cognoscibilidade intersubjectiva, portanto, a possibilidade de compreensão mútua"18. É por esta razão que a corporeidade mediatiza, na medida em que a compreensão dos corpos permite que cada consciência se abra, a partir da sua mónada, a todos os fenómenos do mundo, mundo este que é partilhado por numerosos 'eus'.

\section{IV - Ideen I- II (1912-1928)}

\section{1) A constituição do objecto em geral}

O objecto é constituído intrinsecamente na consciência. Ele só pode ser concebido como cogitatum, isto é, pensado. Ele é o resultado de uma síntese produzida pela motivação intencional do eu. Esta sintese é efectuada pela consciência em contacto com os elementos hyléticos sensiveis. O objecto não é pensável sem uma consciência e, portanto, exige uma "doação de sentido (Sinngebende)"'19. No entanto, não é a partir da subjectividade transcendental que se origina o objecto. A génese do objecto funda-se a partir da convergência de vários elementos, isto é, de uma síntese à maneira kantiana: da unificação entre uma intuição e uma percepção.

Esta síntese deverá ser realizada como uma unidade da experiência intuitiva e da diversidade de perspectivas (Abschattungen) do objecto intencional.

Sendo assim, a subjectividade transcendental não é a matéria da qual brota o 'objecto', mas apenas o poder de realizar esta síntese constitutiva, que é constituída pela intuição doadora e a diversidade de perspectivas que caracteriza o objecto intencional. $\mathrm{O}$ eu não poderá ser concebível sem esta alteridade do objecto. A intencionalidade não surge portanto unicamente por parte do eu, mas em correlação com o objecto; como que se reflecte nele. Desta forma, o eu torna-se de certa maneira "uma permuta intersubjectiva da experiência, num eu real objectivo: 
já não me capto como um eu puro pelas minhas cogitationes puras, mas como um homem objectivo no mundo objectivo, com uma alma objectiva, como eu objectivo real" ${ }^{\prime 20}$.

Com efeito, é nesta alteridade constitutiva do eu que intervém o corpo como terceiro elemento intermediário, no processo de constituição da consciência. "O corpo é uma coisa que goza, no entanto, de um privilégio, pelo facto de ser o ponto de referência, o 'ponto zero' (Nullpunkt), em relação ao qual, no seu aqui constante, localizo as outras coisas" 21 .

É necessário, contudo, verificar de forma descritiva qual a significação do corpo vivente e quais os modos de aparição da corporeidade. Na verdade, na intuição, encontramos as impressões sensíveis que constituem a natureza dos 'sensualia'. Mas, para além disto, encontramos igualmente todo o género de afectos sensíveis, tais como as sensações de prazer, de dor etc. Estas sensações caracterizam-se por serem actos e vivências intencionais da esfera do afecto. Os correlatos intencionais, isto é, noético-noemáticos destas vivências têm uma função hylética e funcionam analogamente à função "das sensações primárias para as vivências intencionais da esfera da experiência" ${ }^{\prime 22}$. Por outras palavras, funcionam analogamente à experiência das sensações na constituição do objecto espacial em geral.

Os conteúdos das sensações são, como diz o próprio Husserl, 'co-entrelaçados" e têm uma localização dada efectivamente pela intuição, na medida em que estão directamente ligados ao corpo. O mesmo não acontece com a intencionalidade, na medida em que esta está em relação com o corpo próprio, unicamente por transposição. A consciência homem está directamente ligada ao seu corpo e esta motivação existe enquanto fundamento hylético. Neste sentido, estas sensações pertencem à consciência do homem de maneira imediata e constituem a natureza 'objectal' do corpo próprio' (die eigene Objektität Leib).

\section{2 ) A constituição subjectiva através do corpo}

É na segunda secção de Ideen $I I$, mais propriamente no capítulo terceiro, do $\S 35$ ao $\S 42$, que Husserl aborda a questão da constituição da realidade psíquica através do corpo (Leib). Na sequência desta abordagem, segue-se de imediato a constituição da realida psíquica intropática. O corpo, enquanto realidade psicofísica, constitui-se em correlação com a natureza material, mas não deve ser pressuposto como coisa material plenamente constituída. O fenómeno da constituição do corpo (Leib) como experiência efectuada através de objectos espaciais é, ele mesmo, uma experiência efectuada pelo homem, enquanto objecto espacial. A percepção dessa experiência do corpo enquanto realidade psico-fisica coloca em evidência uma tripla experiência fundamental do corpo:

a) a experiência do corpo (Körper) enquanto realidade material;

b) a percepção do mundo através do corpo próprio (Leib);

c) finalmente, o complexo dessas sensações numa corporeidade da carne (Leibkörper).

"O corpo próprio constitui-se portanto originariamente sob um duplo modo: por um lado, ele é coisa física, matéria (Materie), ele tem extensão na qual entram

20 A. Morujão, O problema da intersubjectividade na fenomenologia de Husserl, in Revista portuguesa de filosofia, 41,1985, n. $^{\circ} 4$, p. 345.

21 Ideen II, § 41.

22 Ideen II, § 39 
as suas propriedades reais (reale), a coloração, o liso, o duro, o calor, e todas as outras propriedades materiais do mesmo género; por outro lado, eú encontro nele e eu sinto 'sobre' ele e 'nele': o calor da palma da mão, o frio nos pés, as sensações de contacto na ponta dos dedos" 23 .

No sentido de explicitar a função complexa do corpo enquanto complexo de sensações, Husserl estabelece una diferença entre o domínio visual e o domínio táctil para mostrar que as propriedades da sensação não são as propridedades da visão e que nesta diferença entre o 'tocante tocado' e o 'vidente visto', se funda uma diferença constitutiva no corpo próprio. Husserl afirma mesmo que "um sujeito que fosse dotado somente de visão não poderia ter nunca nenhum corpo próprio aparecente" 24 .

A importância dada à função das sensações e das 'sensualia" como esfera fundamental do afecto (Gefühlssphäre) e que estão na base da constituição das objectividades, determina uma certa correlação do corpo próprio (Leib) com as coisas exteriores. Uma vez mais, Husserl estabelece uma diferença entre o corpo próprio visto e o corpo próprio tocado: “Aquilo que eu nomeio um corpo próprio (Leib) não é um vidente visto, como o meu corpo enquanto corpo tocado é um tocante tocado. (...) O papel das sensações da vista é portanto na constituição correlativa do corpo próprio e das coisas exteriores, um papel bem diferente do das sensações do tocar"25.

Só na ordem do sensível táctil, a reflexividade corporal é uma archi-presença originária. Neste sentido, o carácter intropático será de segunda ordem, e, portanto, do domínio da apercepção. Podemos assim concluir que a Einfühlung estará directamente associada ao modo de visão e de apresentação que podemos ter do outro, a partir da nossa própria apresentação. Mas o outro não poderá reduzir-se a esta apresentação imagética dada pela Einfühlung. O modo principial de acesso ao outro é antes de tudo através da sua carnalidade. "O que é reproduzido por imagens é qualquer coisa de distanciado no espaço e eventualmente no tempo (pertencendo eventualmente ao passado). Na Einfühlung, existe uma similitude de co-presentação e apresentação. Devo portanto afirmar que o outro é a minha imagem reproduzida? Isto seria naturalmente um erro. [...] No caso da consciência de imagem, é a 'imagem' que desperta, no caso da consciência de Einfühlung, é o corpo de carne estrangeira que desperta a relação com o meu corpo de carne. [...] $\mathrm{Na}$ consciência de imagem, eu vejo a imagem através da imagem. Na consciência humana, eu vejo o corpo, mas eu não vejo através dele, visto que ele permanece, na verdade, ele mesmo; eu vejo o corpo do outro. É isto que é ele mesmo. E contudo, através dele, eu vejo a carne interior e a partir daí, ainda mais longe"26.

\section{3) A constituição intropática}

A constituição intersubjectiva é objecto de análise a partir do § 43 até ao $\S 47$ de Ideen II. Na verdade, é essencialmente a partir da esfera da constituição originária que se poderá agora passar à constituição do outro, à compreensão

26 Zur Phänomenologie der Intersubjektivität. Husserliana XIV, n. ${ }^{\circ}$ 28, p. 486. Cf. N. Depraz, op. cit. pp.154-155. 
intropática. Com efeito, a esfera da constituição objectal que é caracterizada pela subjectividade individual, deverá ser levada à procura de uma constituição intersubjectiva para uma multiplicidade de sujeitos. A intropatia (Einfühlung), ou a compreensão do outro poderá ser formulada em dois aspectos essenciais: o outro eu constitui-se por semelhança com o próprio eu; o próprio eu constitui-se na sua oposição ao 'objecto'.

Como afirma Husserl "ao contrário, é com a intropatia (Einfühlung) e com a orientação constante da reflexão própria à experiência, relativamente à vida psíquica e, apresentada pelo corpo do outro em constante associação objectiva com este corpo, que se constitui a unidade fechada 'homem', e é ela que eu transfiro em seguida para mim mesmo"27.

$\mathrm{Na}$ verdade, a apercepão do outro não é possível senão graças à mediação do corpo. "O outro é constituído em mim através do corpo do outro, graças à semelhança apreendida em relação ao meu próprio corpo"28. O primeiro momento na compreensão intropática do outro consiste em efectuar uma transferência, do vivido, de uma experiência mediada pelo corpo do outro, para o meu próprio eu. Há assim uma verificação de um corpo que se apresenta como meu. O corpo apresenta-se como centro ao redor do qual se reúne todo o mundo espacial, da mesma maneira que o corpo é o 'ponto de intercâmbio' (Umschlagspunkt) ${ }^{29}$ entre o exterior e o sujeito psico-somático ${ }^{30}$.

A noção de intropatia (Einfühlung) está directamente ligada à experiência do outro por meio da corporeidade: "A característica da intropatia é levar-nos a uma consciência originária do corpo-espírito, de tal género porém, que eu, que não sou o outro, não a posso realizar originariamente, mas apenas funcionar como um analogato que a explica"31.

\section{V-Erste Philosophie (1923-24)}

Nestas lições de Erste Philosophie, do semestre de inverno de 1923-24, $2 .^{\circ}$ volume, Husserl considera a percepção do outro como uma "percepção mediante interpretação originária" ${ }^{32}$.

Segundo I. Kern, nestas lições, bem como nas designadas por Einführung in die Philosophie, do semestre de inverno de 1923/24, Husserl empreende aquilo que designa como um novo começo sistemático para a sua filosofia. É aqui, neste projecto, que elabora a intersubjectividade transcendental, restabelecendo expressamente a redução no seu duplo sentido, tal como tinha feito em 1910-1911.

As primeiras secções destas lições desenvolvem, sob um olhar crítico, a via cartesiana. Descartes traz à evidência um elemento novo que permite edificar, sob o fundamento deste ego cogito como certeza evidente e máxima teórica, toda a

27 Ideen zu einer reinen Phänomenologie und phänomenologische Philosophie. Zweiter Buch. Phänomenologische Untersuchungen zur Konstitution. Haag, Martinus Nijhoff, 1952.

Traduction française de E. Escoubas. Idées directrices pour une phénoménologie et une philosophie phénoménologiques pures. Livre second. Recherches phénoménologiques pour la constitution. Paris, Presses Universitaires de France, 1982, p. 236.

28 J. Fragata, A fenomenlogia de Husserl como fundamento da Filosofia. Braga, Livraria Cruz/ Faculdade de Filosofia de Braga, 1983, p. 162.

29 Cf. J. Fragata, op. cit., p. 162.

30 Ideen II, § 41-42, pp. 226-227.

31 Ideen II, § 51, p. 278.

32 Erste Philosophie. Zweiter Teil. Husserliana VIII. The Hague, Martinus Nijhoff, 1959, p. 63. 
sistematização da verdadeira filosofia. O começo absoluto desta nova forma de interrogar e filosofar é essencialmente fundado na experiência do ego sum como o mundo objectivo da verdade subjectiva que precisa de ser construída e comprovada.

Mas, apesar da nova aportação trazida por Descartes, ao pretender uma fundamentação radical do conhecimento, algo de limitativo traduz a metodologia cartesiana: o ego cogito, na sua pura objectividade transcendental, mais não é do que uma alma pura, uma pequena parte do mundo. Ora, segundo Husserl, a atitude fundamental desta filosofia transcendental é a de poder entender o ego, enquanto existente no mundo pré-dado ${ }^{33}$.

Husserl considera que a redução fenomenológica até aí desenvolvida apresenta algumas limitações, quanto à natureza constituitva do ego cogito. $\mathrm{Na}$ verdade, a redução é apresentada como uma perda do mundo e o ego cogito como o resíduo que resiste a essa perda. Por outro lado, a subjectividade egológica é composta unicamente pelas vivências actualizadas que limitam essa mesma subjectividade. Ora, Husserl afirmará inclusive o seguinte: "Para mim mesmo, reconheço-o, a primeira intuição que eu tive acerca da redução fenomenológica, consistia, e tal como eu a descrevi mais acima, numa concepção bem mais limitada. Durante anos eu não via maneira alguma de transformar a redução, numa redução intersubjectiva" 34 .

Toda a percepção de um objecto situado no espaço comporta uma inadequação entre a consciência e a percepção deste mesmo objecto, na sua ipseidade corporal (Leibhaft Selbstheit). A percepção de qualquer coisa é apreendida a partir de um misto: a partir da doação da coisa ela mesma e da co-intenção (Mitmeinung) directamente ligada a esta percepção.

É precisamente esta co-intenção que é fonte de horizontes abertos e que é responsável pela inadequação presente em qualquer intenção, visto ela denunciar, na sua prática, horizontes não reconhecidos ou mesmo inapercebidos, ou ainda imperfeitamente conhecidos, e que acompanham qualquer percepção da coisa em carne e osso (Leibahft). A essência geral da percepção permanece inadequada, e nela reside esta abertura antecipativa da co-intenção que acompanha qualquer percepção. Por esta razão, estão inerentes a todo o acto de percepção possibilidades abertas a qualquer objecto da experiência; estas mesmas possibilidades exprimem a experiência do 'ser-outro', ou mesmo até do 'não-ser' ${ }^{35}$. É neste sentido que o mundo realmente percebido só pode ser fruto de uma constante correcção, ou antes, de auto-correcção da verdade. Husserl afirma, parafraseando Herbart: "Tanto mais aparência, tanto mais indicação de ser" ${ }^{36}$. Sendo assim, a verdade constituída a cada instante não é senão uma verdade que possui um valor real existente como simples aparência. Contudo, a experiência progride continuamente, pondo simultaneamente em evidência uma correcção da verdade em progressão. Trata-se a aproximação da verdade sempre a ser conquistada, mas inacessível nela mesma.

No entanto, esta mesma perspectiva de uma verdade sempre em progressão, coloca o problema da não existência do mundo ou de qualquer objecto existente no mundo. O simples facto de que eu possa colocar em questão a existência do mundo,

Erste Philosophie. Erste Teil.Tradução francesa de A. L. Kelkel. Philosophie Première. Paris, PUF, 1970, p. 106.

34 Cf. N. Depraz, Transcendence et incarnation, Pp. 207-208. Husserl, citado por R. Böhm na nota de rodapé na 53. ${ }^{\mathrm{a}}$ lição da Erste Philosophie $(175$, n.1). 
só por si, basta-me para que a apodicticidade deste mesmo não-ser possa ser efectivamente afirmada, e ser também objecto da minha experiência.

\section{VI - Cartesianischen Meditationem (1930-31)}

É na quinta meditação cartesiana que o problema da intersubjectividade e particularmente da corporeidade se coloca de forma evidente e problemática. O problema da constituição do ego sum transcendental como exigência da constituição de uma teoria do mundo objectivo coloca, em termos de método fenomenológico, isto é ao nível da redução transcendental, a co-pertença de um alter ego fazendo-se constituinte, enquanto outro do'meu ego.

Husserl formula a problemática da intersubjectividade, questionando o próprio método fenomenológico até aí construído. É sob as bases de uma crítica e de uma aparente aporia em relação a toda a edificação do modelo transcendental egológico dominado pela figura do ego solus ipse, que Husserl resolve responder a essa crítica, a partir do interior da fenomenologia do ego transcendental.

A alteridade constitui-se como contrapolo do eu. O 'outro' faz parte da minha experiência. Neste sentido, ele é um correlato da minha experiência. Mas, para além disso, a percepção do outro, como existente realmente, é o resultado de uma série de experiências 'estrangeiras' ao 'eu'. De certa forma, o 'eu' constitui-se na relação a um mundo de coisas, e este mundo de coisas é diferente de mim. Husserl dá como estabelecido o facto de que "eu tenha em mim, no quadro da minha vida de consciência pura, transcendentalmente reduzida, a experiência do 'mundo' e dos 'outros' - e isto conforme ao sentido mesmo desta experiência - não como se tratasse a obra da minha actividade sintética, em certa medida privada, mas como um modo estrangeiro a a mim, 'intersubjectivo' existente para cada um, acessível a cada um nos seus objectos" ${ }^{\prime 37}$. A experiência do outro é uma experiência que põe o outro como estranho a mim, e ele não poderá ser o mero resultado da minha actividade sintética. O outro é-me acessível através da experiência do seu corpo de outro. Na verdade, o corpo (Leib) experimenta acções e reacções semelhantes às que eu experimento em mim mesmo, no meu corpo próprio. O corpo organismo desempenha aqui a função de analogato.

Vejamos como Husserl consegue demonstar a constituição do alter ego em mim, e do 'outro' enquanto outro. A époché fenomenológica tinha constituído o ego transcendental absoluto. Husserl pretende expor sobre a base da intencionalidade 'explícita e implícita', como se poderá firmar e manifestar o alter ego. Ora para explicitar o alter ego em mim, será necessário mostrar que tipo de intencionalidade está presente neste alter ego. A experiência do outro em mim apresenta-se sob diversas categorias que se impõem como uma experiência concordante do outro. Uma dessas categorias é a apresentação (Vergegenwärtigung) que é distinta do modo próprio de como o ego puro se presenta (Gegenwärtigung) a si mesmo.

A apercepção do outro como realmente existente é experimentada por mim. O outro faz parte dos objectos do mundo, mas não na categoria de 'coisas' da natureza. A experiência que se tem do outro está directamente ligada aos corpos de maneira singular. Eu percebo os outros enquanto sujeitos do mundo e para o mundo. 
Podemos, então, abordar a questão da experiência do outro e da intersubjectividade nas Meditações cartesianas segundo cinco aspectos essenciais: 1 - a esfera da constituição do ego transcendental e do mundo objectivo deste mesmo ego; 2 - a esfera da experiência do 'outro' como correlato onto-noemático do cogito; 3 - a esfera da objectividade do mundo intersubjectivo; 4 - a Einfühlung - a experiência do outro enquanto transcendência do mundo objectivo; 5 - o mundo comum enquanto constituinte do mundo do 'nós'.

Estes cinco passos mais não são do que o processo gradativo da constituição da experiência do outro, mediado pela corporeidade. Sem dúvida, o segredo da constituição do outro assenta realmente no carácter intermediário do corpo organismo (Leib). O outro é constituído em mim através do corpo do outro, graças a uma semelhança com o meu próprio corpo. Por isso se dá, então, a experiência de que o ego se constitui, não como eu mesmo, mas reflectindo-se no meu próprio ego, como um analogon. Ele constitui-se como um alter ego.

Por outro lado, o outro é um reflexo de mim mesmo. Mas eu não posso experimentar o eu do outro, da mesma maneira que experimento o meu próprio eu. A interioridade do outro não pode ser comprovada imediatamente. A compreensão intropática, isto é, a Einfühlung, ou seja a compreensio, passa a ser a mediação necessária para que essa compreensão do outro seja possível. "Foram os conceitos de Paarung e de Einfühlung que permitiram a Husserl a afirmação a objectividade inter-subjectiva, livrando-o do solipsismo" ${ }^{\text {"38. }}$. A célebre doutrina da associação binária, ou Paarung ${ }^{39}$, verifica-se quando "dois elementos se unem destacada mas inseparavelmente na consciência" 40 . O fenómeno da Paarung engloba de forma muito geral a apercepção por semelhança, feita através da experiência do outro. N. Depraz explicita claramente o fenómeno da 'implicação' através de uma esquematização que traduz esta realidade necessariamente pela presença de dois sujeitos, da presença de uma unidade de consciência, e da inevitável diferença no seio destes dois data, finalmente, um modo de unidade destes dois como semelhança a outro.

No entanto, eu não apercepciono o outro como um simples duplo de mim mesmo. O outro tem, na verdade, uma esfera própria tão válida quanto a minha, caracterizada pela carnalidade própria. "O outro é apreendido na apresentação como um 'eu' de um mundo primordial ou uma mónada. Para esta mónada, o seu corpo é que é constituído de uma maneira original e dado sob o modo do hic absoluto, centro funcional da sua acção. Por conseguinte, o corpo do outro, aparecendo na minha esfera monádica, sob o modo do illic, apreendido como organismo corporal do outro, como organismo do alter-ego, é-o, ao mesmo tempo, como o mesmo corpo no mundo do hic, e cuja experiência o outro tem na sua esfera monádica"4l.

\section{VII - Krisis (1935-36)}

Esta obra foi escrita entre 1935 e 1936. A problemática da corporeidade e da intersubjectividade é aqui exposta por Husserl, através de uma via não cartesiana, como forma de acesso ao mundo comum da vida (Lebenswelt).

M. J. Cantista, A evidenciação progressiva do "fenómeno puro» como fundamento radical, in Revista portuguesa de filosofia, 42, 1986, fasc. 3-4, p. 303.

39 Méditations cartésiennes, $§ 51$, p. 95.

40 J. Fragata, A Fenomenologia de Husserl, p. 167.

41 Méditations cartésiennes, § 53, p. 99. 
A époché desenvolve-se numa outra perspectiva fenomenológica, significando duas coisas: a primeira, uma atitude que não visa a abstenção habitual do mundo natural como insignificante; a segunda, uma atitude filosófica que nos leva a olhar para o mundo como recebendo a doação da liberdade total. Passa a existir uma correlação universal entre a consciência e o mundo. Enquanto que na via cartesiana, o método de abstracção aí, era o de atingir um ego transcendental purificado, agora, o novo caminho é o de afirmar o mundo da vida como o novo começo radical: o da predoação (Vorgegebenheit) desse mesmo mundo, como mundo da vida e da acção.

Husserl pretende regredir do mundo do já constituído, aos modos que caracterizam tal constituição. Põe-se entre parêntesis a pretensa originareidade da objectividade científica para se patentear a Ur-Evidenz, a evidência originária do sentido, como sentido da vida quotidiana do sujeito, sobre o qual se constroem as diferentes sistematizações das ciências. Só a adesão completa ao mundo da vida, solo (Boden) universal de todas as teorias e de todas as praxis, afirma o sujeito no encontro consigo próprio. E o sentido deste encontro é a fenomenalização historico-transcendental da humanidade. A subjectividade transcendental fenomenaliza-se como universalidade a estrutura intersubjectiva, cujo ingrediente essencial é o tempo e a história, história da razão universal teleologizada.

O novo olhar da experiência conduz-nos de tal forma que "esta operação de uma redução do 'mundo' ao fenómeno transcendental 'mundo' e de imediato ao seu correlato: a subjectividade transcendental", nos é dado, antes mesmo de toda a ciência. "É preciso que o olhar que a époché liberta seja, também ele, à sua maneira, um olhar da experiência. Operar uma inversão total desta atitude, deve consistir nisto, que a infinidade da experiência mundana real e possível se transforme numa infinidade de experiência transcendental real e possível"42. Esta nova époché é dada de forma imediata e como uma necessidade absoluta.

A via cartesiana do ego transcendental operava por sucessivas etapas abstractivas, de tal forma que, por saltos gradativos, se chegava a um ego purificado. Ora o contrário desta posição, é aquela que afirma a prioridade do mundo da vida (Lebenswelt), do mundo no qual vivemos intuitivamente, isto é, o mundo ambiente da vida, como sendo o novo horizonte do aparecimento do mundo e das coisas. A percepção é uma experiência singular, a partir da qual o ente se pode dar. É sob este ponto de vista que ele se dá como um modo particular do sensível, diferente dos outros, que pertencem à exposição dos diferentes campos de sensações, como seja, por exemplo, o campo sensível e o campo do tocar.

Nesta perspectiva, Husserl pretende atingir o limiar a priori universal, como resultante de uma époché que opera, não segundo um modo isolado e singular do fluxo contínuo da consciência, mas na partilha da vida com os outros (Miteinanderleben). Só desta forma se poderá assim chegar a uma validação do mundo enquanto horizonte universal comum a todos os homens. Da mesma maneira, o campo preceptivo é agora entendido como um horizonte aberto a diferentes percepções possíveis. "Desde que se começa, em vez de sermos orientados sobre as coisas, os objectos do mundo da vida, para os conhecer como eles são, começamos, pelo contrário, a interrogá-los sobre os modos de doação subjectiva. (...) Logo de imediato chegamos a um reino de descobertas que se complicam cada vez mais e que são impressionantes. (...) Na reflexão, reconhecemos com espanto que existem correlações de essências que são os elementos a priori, que vai mais 
longe, um a priori universal. E que maravilhosas 'implicações' se mostram aí, que por acréscimo são com efeito apreendidas descritivamente" 43 .

A constituição intersubjectiva é a condição sine qua non para uma compreensão da intencionalidade que não é mais do foro subjectivo isolado, mas de uma totalidade intersubjectiva. Este mundo objectivo, na sua totalidade, afirma-se essencialmente como intersubjectivo. Husserl declara mesmo que "a constituição do mundo comunitário se funda numa experiência do outro"44.

A constituição do ego individual faz-se a partir de uma multiplicidade de egos que afirmam, na sua identidade, o seu próprio 'eu'. Por esta razão, é só na medida em que existe esta universalidade de eus, que se constitui uma intersubjectividade enquanto tal, de nós-todos, a partir de mim e 'em' mim. O ego constitui-se assim um outro enquanto outro. Mas ainda mais: a temporalidade que constitui o fluxo contínuo na actualização do ego, e toma parte essencial na esfera primordial deste mesmo ego, enquanto analogia com a minha experiência intropática, revela uma "presença originária simplesmente presentificada". Existe assim, uma relação analógica entre uma temporalização do ego passado, isto é a Entgegenwärtigung e a a experiência do outro (Entfremdung), enquanto constituinte do alteridade do próprio eu.

Desta forma, Husserl conclui existir no eu, um 'outro' eu que acede ao nível de ser enquanto co-presente e com todos os modos de validação evidentes, mas que não são unicamente os da percepção sensível.

$\mathrm{Na}$ Krisis, Husserl procura o valor constitutivo da esfera objectiva ego transcendental que não seja somente afirmado pelo seu valor individual e isolado; pelo contrário, pretende-se que através de uma modificação do valor intencional deste ego e da sua primordialidade, se tenha acesso a um valor de Ser que passe necessariamente pela 'percepção do outro'.

A relação do corpo e da alma na explicação pré-científica é, segundo Husserl, de identificação, embora estas duas realidades sejam como que duas partes justapostas, uma fora da outra e, por isso, também separadas uma da outra.

A noção de corporeidade participa da real forma universal que é a espácio-temporalidade. É nesta forma que se dá a existência dos corpos e das almas. A experiência a temporalidade e a espacialidade que não seja unicamente a da corporeidade dos corpos mas sim das almas, é dada de forma originária a cada um.

Do mesmo modo, todos os objectos do mundo são e podem ser corporeizados. Todos eles participam do espaço-tempo do corpo. Mas a significação espiritual desta corporeidade resulta da maneira como ela é possuída. A experiência da corporeização das almas é experimentada de forma originária por cada um, em si mesmo. "O que significa na sua própria essência, o facto de ser de carne, eu só o experimento sobre a minha carne, a saber e na minha constante dominação imediata - e unicamente neste mesmo corpo"45. A experiência de ser-carne é provada de maneira singular, originariamente e de forma imediata. Mas, no entanto, é necessária a corporeização de qualquer objecto, e em especial dos objectos que permitem essa espiritualização corporal. Assim sendo, todos os outros 'eus' corporais possuem esta mesma capacidade, e é nesta base que se efectua toda a experiência com o mundo.

${ }_{43}$ Krisis, $\S 46$, pp. 180-181.

44 Zur Phänomenologie der Intersubjektivität, III. Autour des méditations cartésiennes (1929-1932). Tradução francesa de N. Depraz, P. Vandevelde. Revista por M. Richir. Grenoble, Jérôme Millon, 1998, p. 81.

45 Krisis, § 62, p. 244. 
$\mathrm{Na}$ verdade, é porque eu experimento na minha corporeidade de carne enquanto experiência imediata e original, que eu posso compreender os outros 'eus' enquanto corpos que se 'corporeizam'. Tal compreensão é-me dada de forma mediata. Todo e qualquer sujeito egológico possui o seu próprio corpo localizado num espácio-tempo. "Um corpo é o que é, enquanto corpo aqui determinado, substrato único, localizado espácio-temporalmente, e de propriedades causais. (...) Mas o 'eu' é, ele mesmo, e possui a individualidade em si mesmo e por si mesmo, não a possui a partir da causalidade. Na verdade, graças à sua carne corporal, pode distinguir-se de qualquer outro 'eu' e portanto de todo o mundo"46.

É a corporeidade da carne que individualiza cada 'eu' e é nesta base que a relação interpessoal poderá ser feita.

Em síntese: na essência do eu, há pois uma alteridade que a marca originariamente. Esta alteridade vê-se reforçada nas últimas obras de Husserl, em íntima conexão com o tema da experiência do outro e da intersubjectividade incarnadas. O tema do Outro, por antonomásia - Deus - insere-se neste contexto, e é abordado ao longo de toda a obra husserliana, em íntima conexão com as diferentes etapas redutivas. Não abordamos aqui este tema por transcender os objectivos do presente artigo. 